\title{
O ral Candida Flora from Brazilian Human Immunodeficiency Virus-infected Patients in the Highly Active Antiretroviral Therapy Era
}

\author{
NR Melo/ ${ }^{+}$, H Taguchi**, J Jorge, RJ Pedro*, O P Almeida, K Fukushima**, K Nishimura**, \\ M Miyaji**
}

\begin{abstract}
Departamento de Patologia Oral, Faculdade de Odontologia de Piracicaba, Piracicaba, SP, Brasil *Departamento de Moléstias Infecciosas, Faculdade de Ciências Médicas, Unicamp, Campinas, SP, Brasil **Research Center for Pathogenic Fungi and Microbial Toxicoses, Chiba University, Chiba, Japan
\end{abstract}

One of the main opportunistic fungal infections amongst immunocompromised individuals is oral candidosis, which has been found in up to $90 \%$ of human immunodeficiency virus (HIV)-infected patients. This study employed yeasts isolated from the saliva and oral cavities of 114 HIV-infected patients living in Campinas, São Paulo. Of the isolates, $57.8 \%$ were identified as Candida albicans and $42.1 \%$ as non-C. albicans. The latter isolates were subsequently identified as C. krusei (7.5\%), C. lusitaniae (5.2\%), C. tropicalis (4.6\%), C. parapsilosis (4.6\%), C. glabrata $(2.8 \%)$, C. kefyr (1.7\%), C. guilliermondii (1.7\%), C. intermedia (1.1\%), C. norvegensis $(0.5 \%)$, and Rhodotorula rubra $(1.7 \%)$. Susceptibility of the isolates to amphotericin B, fluconazole, miconazole, and itraconazole was also determined by a microdilution method adopted by the National Committee for Clinical Laboratory Standards. The isolates demonstrated various susceptibilities to the antifungal agents. In particular $29 \mathrm{C}$. albicans and 13 non-C. albicans isolates showed low susceptibility to FLCZ (> $64 \mu \mathrm{g} / \mathrm{ml})$. This study revealed huge diversity of Candida species, in particular the increasing emergence of non-C. albicans associated with the oral flora of HIV-infected patients.

Key words: Candida - human immunodeficiency virus - antifungal drug - Brazil

Since the human immunodeficiency virus (HIV) was described in the 1980s, the number of HIV-infected patients has continued to increase and at present over than 50 million patients have been documented in the world. Furthermore, opportunistic fungal infections in immunocompromised hosts have become a serious problem in the medical field (Pfaller et al. 1998). In particular oral candidosis occurs in more than $90 \%$ of HIV-infected patients (Korting et al. 1999). Usually the main causative agent of oral candidosis in immunocompromised hosts is Candida albicans, which is a member of oral microbe flora (Odds 1984, Stenderup 1990, Fetter et al. 1993). Nevertheless, in recent years several reports have described a change of oral Candida flora in HIV-infected patients (Nguyen et al. 1996, Nho et al. 1997). This change has been particularly associated with the use of antifungal agents such as fluconazole (FLCZ). FLZC has been the primary choice in fungal infection therapy for HIV-infected patients (Ghannoum \& Rice 1999). However, an increas-

Financial support: Japan International Cooperation Agency, Japan National Institute of Infectious Diseases, and Fundação de Amparo à Pesquisa do Estado de São Paulo (grant 97/07020-2) ${ }^{+}$Corresponding author present address: Swansea Clinical School, Grove Building, University of Wales Swansea, Wales SA28PP, UK. Fax: +44-01792-602.046. E-mail: nadjarm@yahoo.com

Received 19 November 2003

Accepted 26 May 2004 ing number of patients with clinical resistance to this azole antifungal compound has been observed (Le Guennec et al. 1995). Resistance to antifungal agents has important implications for morbidity, mortality, and health care costs in hospitals as well as in the community. Hence, substantial attention has been focused on improving methods to detect resistance, designing more effective antifungals against resistant organisms and preventing the emergence and spread of resistance in the first place (Nho et al. 1997). The purpose of this study was to evaluate Candida spp. diversity in the oral cavity of HIV-infected patients and to determine the level of resistance of the clinical isolates to antifungal agents.

\section{MATERIALS AND METHODS}

Isolates from HIV-infected patients - One hundred and seventy three isolates were identified from the oral cavities of 114 HIV-infected patients at the School of Medical Sciences, University of Campinas, state of São Paulo, from August 1997 to January 1999. The patients were classified into 4 groups: A2, B2, B3, and C3, according to the criteria defined by the Review System of Classification of the Center for Disease Control and Prevention (CDC 1993). This classification system for HIV infection emphasizes the clinical importance of the CD4+ T-lymphocyte count in the categorization of HIV-related clinical conditions. Categories 1 to 3 correspond to CD4+ T-lymphocyte counts per microliter of blood. Category 1 denotes cell counts greater than or equal to $500 \mathrm{cells} / \mathrm{ml}$; category 2 indicates cell counts of 200-400 cells $/ \mathrm{ml}$, and category 3 means cell counts less than 200 cells $/ \mathrm{ml}$. Category A includes asymptomatic HIV infection. Category B consists 
of symptomatic conditions in HIV-infected adolescent or adult such as bacillary angiomatosis, candidosis oropharyngeal, candidosis vulvovaginal; cervical dysplasia, oral hairy leukoplakia, and constitutional symptoms. Category $\mathrm{C}$ includes the 23 clinical conditions listed in the AIDS surveillance such as candidosis of bronchi, trachea, lungs or esophagus. The group $\mathrm{C} 3$ was the most frequent (41.2\%), followed by the B2 (32.4\%), B3 (18.4\%), and A2 (7.8\%) groups.

The patients were on highly active antiretroviral therapy (HAART) that included Indinavir (HIV protease inhibitors), Zidovudina (AZT), Lamivudine (3TC) or other antiretroviral drugs namely, Didanosine, Zalcitabine, Stavudine, Ritonavir, and Saquinavir. Furthermore, patients with fungal infections were treated with oral antifungal and local antifungal agents (itraconazole gel, chlorhexidine rinse or itraconazole pastilles) in addition to oral hygiene orientation. There were 74 males and 40 females; the average age was $35.2 \pm 8.2$ years. They were racially classified as 95 whites, 9 blacks, and 10 mulattos.

Isolates from healthy subjects - Thirty-one isolates from 30 healthy individuals were examined in this study as a control. They did not receive any drugs such as antibiotics, antiretroviral or antifungal agents. There were 17 males and 13 females and the average age was $47.7 \pm$ 8.2 years. They were racially classified as 20 whites, 5 blacks, and 5 mulattos.

All isolates were cultured and stored according to the standard procedures (Sandven 1990).

\section{Identification}

Conventional methods - The isolates were identified according to the standard technique (Sandven 1990). They were cultured on corn meal agar (Difco, US), supplemented with $1 \%$ Tween 80 , at $25^{\circ} \mathrm{C}$ for 7 days for chlamydospore formation. Germ tube formation was carried out in calf serum (Gibco BR, US) at $37^{\circ} \mathrm{C}$ for 2 to $4 \mathrm{~h}$. Additionally the isolates were cultured at $30^{\circ} \mathrm{C}$ for $48 \mathrm{~h}$ on chromogenic agar (CHROMagar ${ }^{\circledR}$, France) (Beighton et al. 1995), and tested with the Candida Check kit ${ }^{\circledR}$ (Iatron laboratories, Inc., Japan) and ID32C ${ }^{\circledR}$ profiled (bioMerieux, Marcy l'Etoile, France).

Ubiquinone system - Additionally some non-C. albicans isolates were identified by using the ubiquinone system and genetic analyses. C. guilliermondii (ubiquinone 9, Q9) was used as a control. Briefly, ubiquinones were extracted from mycelia grown in Sabouraud dextrose broth. Extraction, purification and determination of ubiquinones by high performance liquid chromatography were performed as previously described (Billon-Grand 1987, Fukushima et al. 1993).

Genetic analysis - The D1/D2 region of the large subunit ribosomal DNA (LSUrDNA) of the same set of samples was sequenced. Genomic DNA extraction from yeast and gram-positive bacteria was carried out using GenTLE ${ }^{\mathrm{TM}}$ (Tanaka Shuzo Co. Ltd, Otsu, Shiga, Japan) according to the manufacturer's instructions. D1/D2 regions were amplified by the method of Kurtzman and Robnett (1997) using a primer set of (NL-1 5'-GCATATCAATAA GCGGAGGAAAAG) and (NL-4 5'-GGTCCGTGTTT CAAGACGG). Amplification was performed for 30 poly- merase chain reaction (PCR) cycles with annealing at $52^{\circ} \mathrm{C}$, extension at $72^{\circ} \mathrm{C}$ for $2 \mathrm{~min}$, and denaturation at $94^{\circ} \mathrm{C}$ for 1 $\mathrm{min}$. The amplified DNA was purified with SUPREC ${ }^{\mathrm{TM}_{-}}$ according to the manufacturer's instructions (Takara Bio Inc., Otsu, Shiga, Japan). The PCR amplified D1/D2 regions were directly sequenced in both directions using a Thermo Sequenase II Dye terminator cycle sequencing Kit (Amersham Pharmacia Biotech, Buckinghamshire, UK) by an AbI PRISM ${ }^{\mathrm{TM}} 377$ sequencer. To determine the sequences, the two following internal primers were adopted together with the above external primers: (NL-2 5'CTTGTTCGCTATCGGTCTC) and (NL-3 5'-GAGA CCGATAGCGAACAAG). The nucleotide sequence data were analyzed by the genetic information processing software, GENETYX-MAC 9.0, 1r 5 (Software Development, Tokyo, Japan).

\section{Antifungal susceptibility test}

Antifungal susceptibility tests were performed using the broth microdilution method according to the guidelines recently published by the National Committee for Clinical Laboratory Standards (NCCLS 1997).

Medium - RPMI-1640 medium (Nissui Pharmaceutical Co., Japan) was buffered with morpholinepropanesulfonic acid (MOPS; Sigma Chemical Co.) and adjusted to $\mathrm{pH} 7.0$ (Taguchi et al. 1995).

Antifungal agents - Amphotericin B (AMPH) (BristolMyers Squibb), fluconazole (FLCZ) (Pfizer Pharm. Inc. Japan), miconazole (MCZ) (Mochida Pharm. Inc. Japan), and itraconazole (ITCZ) (Janssen-Kyowa Co., Ltd., Japan) were tested against the isolates.

Procedures - These antifungal reagent-grade powders were dissolved in dimethyl sulfoxide solvent (DMSO) to obtain stock solutions of $12.8 \mathrm{mg} / \mathrm{ml}$. A 10 -fold serial dilution was performed in RPMI-1640 medium to provide a working solution for each drug giving final concentration ranges of 0.03 to $16 \mu \mathrm{g} / \mathrm{ml}$ for AMPH B, 0.125 to $64 \mu \mathrm{g} / \mathrm{ml}$ for FLCZ, 0.06 to $32 \mu \mathrm{g} / \mathrm{ml}$ for MCZ, and 0.015 to $8 \mu \mathrm{g} / \mathrm{ml}$ ITCZ. Antifungal agents were serially diluted in 96-well microtiter plates (Falcon, Lincoln Park, NJ). The isolates were subcultured onto PDA slants at $30^{\circ} \mathrm{C}$ for $24 \mathrm{~h}$. Cell suspensions were prepared in RPMI-1640 medium and were adjusted to give a final concentration approximately $2.5 \times 10^{3} \mathrm{cells} / \mathrm{ml}$. The microdilution plates were incubated at $30^{\circ} \mathrm{C}$ and the MICs were determined visually at 24 and $48 \mathrm{~h}$. The minimal inhibitory concentration (MIC) was defined as the lowest concentration of antifungal agent at which $80 \%$ inhibition of growth $\left(\mathrm{MIC}_{80}\right)$ occurs compared with that of the growth control well. C. albicans ATCC 90028 and ATCC 90029 were used in each microdilution set to ensure quality control. Chi-Square test and Fisher's exact test were applied considering significant differences of $p<0.05$. Breakpoints for antifungal susceptibility have been established for Candida isolates tested according to NCCLS.

\section{RESULTS AND DISCUSSION}

Oral yeast flora of healthy subjects and HIV-infected patients - Since the AIDS epidemy the oral candi is has been one of the major markers of HIV disease ogression. The prevalence of oropharingeal coloniz on 
and infection by $C$. albicans has been evaluated worldwide (Cassone et al. 1999, Arribas et al. 2000, Diz et al. 2001). Recently several reports have addressed to the impact of HIV protease inhibitor therapy on Candida spp. colonization (Cassone et al. 1999, Mata-Essayag et al. 2001, Barchiesi et al. 2002). Highly active antiretroviral therapy that includes HIV aspartyl protease inhibitors (PIs) causes a decline in the incidence of some opportunistic infections in AIDS, and this decline is currently attributed to the restoration of specific immunity. Besides the expected immunorestoration, patients receiving PI therapy may benefit from a direct anticandidal activity of these drugs (Cassone et al. 1999). In Brazil and South America there are a small number of reports (Mata-Essayag et al. 2001, Sant' ana et al. 2002) focusing on the epidemiology of $C$. albicans and emergent non-C. albicans species in HIVinfected patients after the introduction of HAART. In the present study $100 \%$ of the patients were on HAART. This is the first Brazilian investigation focusing the impact of HIV protease inhibitors on Candida spp. oral colonization. As shown in the Table I, 57.8\% of isolates in HIVinfected patients were C. albicans. Diz et al. (2001) found a similar percentage of $C$. albicans isolates in HIV-infected patients who were treated with HIV protease inhibitors. The data shown by the authors were different from those reported by Hauman et al. (1993). These last authors investigated yeast flora from the oral cavities of HIV-infected patients who had not taken the HIV protease inhibitor drugs. According to their data, C. albicans was still the main isolate. In a multicenter Brazilian study of oral Candida from AIDS patients performed by Sant'Ana et al. (2002), only 37\% of the patients enrolled were on HAART. C. albicans was the most prevalent isolate (91\%) and only $9 \%$ of isolates were non-C. albicans spp. In contrast our data show an increase of the number and species of non- $C$. albicans isolates. Non-C. albicans occupied $42.1 \%$ of the isolates (Table I). They were as follows: 13 of $C$. krusei, 9 of $C$. lusitaniae, 8 of $C$. tropicalis, 8 of C. parapsilosis, 5 of C. glabrata, 3 of $C$. kefyr, 3 of $C$. guilliermondii, 2 of $C$. intermedia, 1 of $C$. norvegensis, 18 of Candida spp., and 3 of $R$. rubra.
Nguyen et al. (1996), Dondra et al. (1996), and Fidel et al. (1999) also indicated that non-C. albicans spp. play a role as causative agents in oral candidosis. Recently, several reports have also described a change in the oral Candida flora of HIV-infected patients (Cartledge et al. 1999, Arribas et al. 2000, Diz et al. 2001). The use of various medicines such as antiretroviral agents, antibiotics, and antifungal agents has been pointed as a reason for this change. Furthermore, other authors (Franker et al. 1990, Fotos \& Hellstein 1992) reported that the oral Candida flora in patients who had not taken HIV protease inhibitors was occupied with $C$. albicans up to $80 \%$. Non-C. albicans spp. have been associated with severe symptoms in oral candidosis and have had a major impact in clinical presentation (Redding et al. 2000). In addition, Colombo et al. (1999) indicated that candidemia due to non-C. albicans is increasing in Brazilian tertiary hospitals. Therefore our results emphasized the emergence of non- $C$. albicans species recently reported (Nguyen et al. 1996, Schoofs et al. 1998, Colombo et al. 1999). Interestingly, no $C$. $d u$ bliniensis isolates were found in our study. C. dubliniensis isolates have been rarely reported in South America, which includes Brazil and Argentina (Rodero et al. 1998, Sano et al. 2000, Mariano et al. 2003) with low incidence of 1.5-2\% compared with $14 \%$ incidence in worldwide reports (Sullivan et al. 1995, Pinjon et al. 2003). Rare Candida spp. such as C. lusitaniae, C. kefyr, C. inter$m e$-dia, and $C$. norvegensis found in our study have been currently isolated and associated with immunocompromised patients (Krcmery \& Barnes 2002). In healthy subjects, C. albicans represented almost all of the yeasts (26 isolates) (Table I); others were $C$. tropicalis (1 isolate), $C$. krusei (1 isolate), Candida spp. (2 isolates), and Rhodotorula rubra (1 isolate). As shown in the Table I, oral yeast flora of the healthy subjects was monotonous and a similar percentage of $15.9 \%$ for non-C. albicans was reported by Schoofs et al. (1998). C. albicans serotype-A was the most prevalent phenotype of $C$. albicans isolates in both groups studied. This result is in accordance with previous reports (Sant'Ana et al. 2002, Mariano et al. 2003).

TABLE I

Yeasts isolated from 173 samples of human immunodeficiency virus (HIV)-infected patients and 31 healthy subjects

\begin{tabular}{|c|c|c|c|c|}
\hline Species & HIV group $(n=173)$ & $\%$ & Healthy subjects $(\mathrm{n}=31)$ & $\%$ \\
\hline Candida albicans $-A$ & 70 & 40.4 & 22 & 70.9 \\
\hline Candida albicans-B & 30 & 17.3 & 4 & 12.9 \\
\hline Candida krusei & 13 & 7.5 & 1 & 3.2 \\
\hline Candida lusitaniae & 9 & 5.2 & - & - \\
\hline Candida tropicalis & 8 & 4.6 & 1 & 3.2 \\
\hline Candida parapsilosis & 8 & 4.6 & - & - \\
\hline Candida glabrata & 5 & 2.8 & - & - \\
\hline Candida kefyr & 3 & 1.7 & - & - \\
\hline Candida guilliermondii & 3 & 1.7 & - & - \\
\hline Candida intermedia & 2 & 1.1 & - & - \\
\hline Candida norvegensis & 1 & 0.5 & - & - \\
\hline Rhodotorula rubra & 3 & 1.7 & 1 & 3.2 \\
\hline Candida spp. & 18 & 10.4 & 2 & 6.4 \\
\hline Candida albicans & 100 & 57.8 & 26 & $(83.8)$ \\
\hline Non-C. albicans & 73 & 42.1 & 5 & (16.1) \\
\hline
\end{tabular}


Analysis of ubiquinone systems and nucleotide sequences of DI/D2 regions of LSUrDNA - When the authors attempted to identify the yeasts isolated from the oral cavities of HIV-infected patients by using conventional methods, some isolates were difficult to identify. In the cases of rare Candida spp., such as $C$. lusitaniae, $C$. kefyr, $C$. intermedia, and $C$. norvegensis, ubiquinone analysis was useful to identify these isolates. The major ubiquinone of each isolate was determined (Table II); $C$. lusitaniae isolates showed ubiquinone-8 (Q8), $C$. intermedia Q9, Q6 for C. kefyr, Q9 for C. guilliermondii, and Q7 for C. norvegensis.

For confirmation of identification of the three rare species, $C$. kefyr, C. intermedia, and C. norvegensis, the nucleotide sequences of the D1/D2 regions of LSUrDNA were analyzed. Nucleotide differences between the isolates examined and those deposited in GeneBank by Kurtzman (Kurtzman \& Robnett 1997) are summarized in Table II. No major difference was found among C. kefyr, C. intermedia, and $C$. norvegensis isolates, which showed only one nucleotide substitution; C. guilliermondii showed two substitutions. Identification methods based on ubiquinone presence have been mainly applied in Chemotaxonomy (Billon-Grand 1987, Fukushima et al. 1993). The chemotaxonomic and genetic data obtained in this investigation supported the conventional methods, therefore the eventual application of chemotaxonomic data to identification particularly in rare species possessing a specific ubiquinone can be an useful alternative.
Relationship between oral yeast flora and progress of HIV-disease - Table III shows the relationship between the yeast flora and CDC criteria (CDC 1993). The number and diversity of Candida spp. increased in proportion to the progress of HIV disease. Interestingly, rare Candida spp. such as $C$. lusitaniae, $C$. norvegensis, and $C$. intermedia were isolated from the oral cavities of HIV-infected patients. In the relationship between Candida spp. and CDC classification in HIV-infected patients, the isolates from the initial AIDS stage patients contrasted with those from the severe disease stage. In the B2, B3, C3 stages, we succeeded in isolating several Candida species. The non-C. albicans isolates $(91.7 \%, 67 / 73)$ were isolated from patients in the advanced stages (B2, B3 and C3 groups). Redding et al. (2000) reported that late-stage HIV-infected patients have high prevalence of Candida spp. with decreased susceptibility to FLCZ, especially non-C. albicans species. Non-C. albicans spp. are therefore more likely to require higher doses of FLCZ in order for the patients to be cured of fungal infections/ disease. The presence of non-C. albicans isolates may be a consequence of immunodeficiency and action of drug therapy (Sweet 1997). Interestingly, C. glabrata was predominant in groups A2 and $\mathrm{B} 2$ compared to $\mathrm{B} 3$ and $\mathrm{C} 3$. On the other hand, $4 C$. lusitaniae isolates were found in the $\mathrm{B} 2$ group. This fact is of particular importance because C. lusitaniae has the ability to develop resistance to AMPH, as reported by Nguyen et al. (1996).

Effect of antifungal agents on the yeasts isolated from

TABLE II

The major ubiquinone and nucleotide differences in LSUrDNA region D1/D2

\begin{tabular}{lcccc}
\hline Species & $\mathrm{n}$ & $\begin{array}{c}\text { Major } \\
\text { ubiquinone }\end{array}$ & $\begin{array}{c}\text { Nucleotide } \\
\text { differences }\end{array}$ & $\begin{array}{c}\text { GeneBank } \\
\text { accession nr }\end{array}$ \\
\hline Candida kefyr & 3 & Q6 & 1 & U94924 \\
Candida norvegensis & 1 & Q7 & - & U75730 \\
Candida lusitaniae & 9 & Q8 & 0 & - \\
Candida intermedia & 2 & Q9 & 2 & U44809 \\
Candida guilliermondii & 1 & Q9 & U45709 \\
\hline
\end{tabular}

TABLE III

Distribution of yeasts in human immunodeficiency virus (HIV)- infected patients according to HIV disease stage ${ }^{a}$

\begin{tabular}{lcccc}
\hline Species & $\mathrm{A} 2(\mathrm{n}=12)$ & $\mathrm{B} 2(\mathrm{n}=51)$ & $\mathrm{B} 3(\mathrm{n}=30)$ & $\mathrm{C} 3(\mathrm{n}=80)$ \\
\hline Candida albicans- $A$ & 4 & 19 & 17 & 30 \\
Candida albicans $-\mathrm{B}$ & 2 & 10 & 4 & 1 \\
Candida tropicalis & - & 2 & 2 & 5 \\
Candida krusei & 1 & 2 & - & 8 \\
Candida kefyr & 1 & 1 & 1 & 1 \\
Candida parapsilosis & 1 & 3 & 1 & 3 \\
Candida glabrata & 2 & 2 & - & - \\
Candida lusitaniae & - & 4 & 1 & 5 \\
Candida guilliermondii & - & 2 & 1 & - \\
Candida norvegensis & - & - & - & 2 \\
Candida intermedia & - & - & 2 & 10 \\
Candida spp. & - & - & - & 2 \\
Rhodotorula rubra & 1 & &
\end{tabular}

a: CDC classification 
the oral cavity - The prevalence of azole resistance among Candida spp. isolates has been variable both over time and geographical location. In the HIV-infected patients, minimal inhibitory concentration (MIC) ranges were wide and some isolates showed low susceptibility against antifungal agents. Table IV summarizes the effect of 4 antifungal agents on the yeast isolates. Amongst HIV-infected patients, 29 C. albicans and 13 non-C. albicans isolates showed low susceptibility to FLCZ (> $64 \mu \mathrm{g} / \mathrm{ml}$ ). Many isolates (80 C. albicans and 63 non-C. albicans) showed low susceptibility to ITCZ (> $2 \mu \mathrm{g} / \mathrm{ml})$. Interestingly, $23 C$. albicans isolates showed a simultaneously low susceptibility to FLCZ (> $64 \mu \mathrm{g} / \mathrm{ml})$ and ITCZ $(>8 \mu \mathrm{g} / \mathrm{ml})$. In contrast, Colombo et al. (1999) described that nosocomial candidemias in Brazilian tertiary hospitals were predominantly caused by non-C. albicans isolates, in which FLCZ resistant isolates were rare. We compared the MIC range of C. albicans serotypes and found that $30 \%$ (21/70) of serotype A had low susceptibility to FLCZ (> $64 \mu \mathrm{g} / \mathrm{ml})$ and ITCZ (> $8 \mu \mathrm{g} / \mathrm{ml})$. Only $6.6 \%$ (2/30) of serotype B displayed a low susceptibility to FLCZ (> $64 \mu \mathrm{g} / \mathrm{ml})$ and ITCZ $(>8 \mu \mathrm{g} / \mathrm{ml})$. Of the $C$. krusei isolates, $41.6 \%(5 / 13)$ revealed cross-resistance to FLCZ $(>64 \mu \mathrm{g} / \mathrm{ml})$ and ITCZ (> $8 \mu \mathrm{g} / \mathrm{ml}$ ). In the case of C. glabrata, $60 \%$ (3/5) of isolates showed a MIC range of $>32 \mu \mathrm{g} / \mathrm{ml}$ for FLCZ and $>4$ $\mu \mathrm{g} / \mathrm{ml}$ for ITCZ; Nguyen et al. (1996) reported similar results. Thus, in this study, $17.8 \%$ (13/73) non-C. albicans isolates in this study showed cross-resistance to the FLCZ (> $64 \mu \mathrm{g} / \mathrm{ml})$ and ITCZ $(>8 \mu \mathrm{g} / \mathrm{ml})$, in contrast to the reports by Pfaller et al. (1998), and Colombo et al. (1999) in which non-C. albicans were susceptible to FLCZ. Antifungal susceptibility of non-C. albicans species varies significantly in contrast to $C$. albicans. Some non- $C$. albicans species are inherently or secondarily resistant to FLCZ, for example, $75 \%$ of $C$. krusei isolates, $35 \%$ of $C$. glabrata, $10-25 \%$ of $C$. tropicalis and C. lusitaniae (Krcmery \& Barnes 2002). Amphotericin B resistance is also seen in a small proportion: $5-20 \%$ of $C$. lusitaniae and $C$. rugosa, $10-15 \%$ of $C$. krusei and $5-10 \%$ of $C$. guilliermondii. The isolates from healthy subjects showed narrow minimal inhibitory concentration (MIC) ranges. Five $C$. albicans isolates showed low susceptibility (> $2 \mu \mathrm{g} / \mathrm{ml}$ ) to ITCZ but all C. albicans isolates from healthy subjects were susceptible to FLCZ $(0.12-8 \mu \mathrm{g} / \mathrm{ml})$. Certain non-C. albicans species such as $C$. glabrata and C. krusei are commonly less susceptible to FLCZ than $C$. albicans and are being isolated with increased frequency in HIV-infected patients (Redding et al. 2000). In our study only one $C$. krusei isolate from the healthy subjects showed low susceptibility to FLCZ (> $64 \mu \mathrm{g} / \mathrm{ml}$ ) emphasizing that this organism is intrinsically resistant to FLCZ (Fukuoka et al. 2003).

In conclusion, according to recent reports, an increase in Candida spp. diversity in the oral cavities of HIV-infected patients is evident. The presence of isolates with low susceptibility to antifungal agents in our study represents a serious problem for the selection of effective antifungal therapy. An increase of recurrent non- $C$. albicans candidemia episodes with antifungal resistance has also been suggested. Therefore, greater attention should be paid to microbiology routine problems encountered to ensure that non-C. albicans spp. are accurately identified. Our study revealed huge Candida spp. diversity and relevant emergence of rare non-

\section{TABLE IV}

Minimal inhibitory concentration values $(\mu \mathrm{g} / \mathrm{ml})$ of the isolates from the healthy subjects and human immunodeficiency virus (HIV)-infected patients

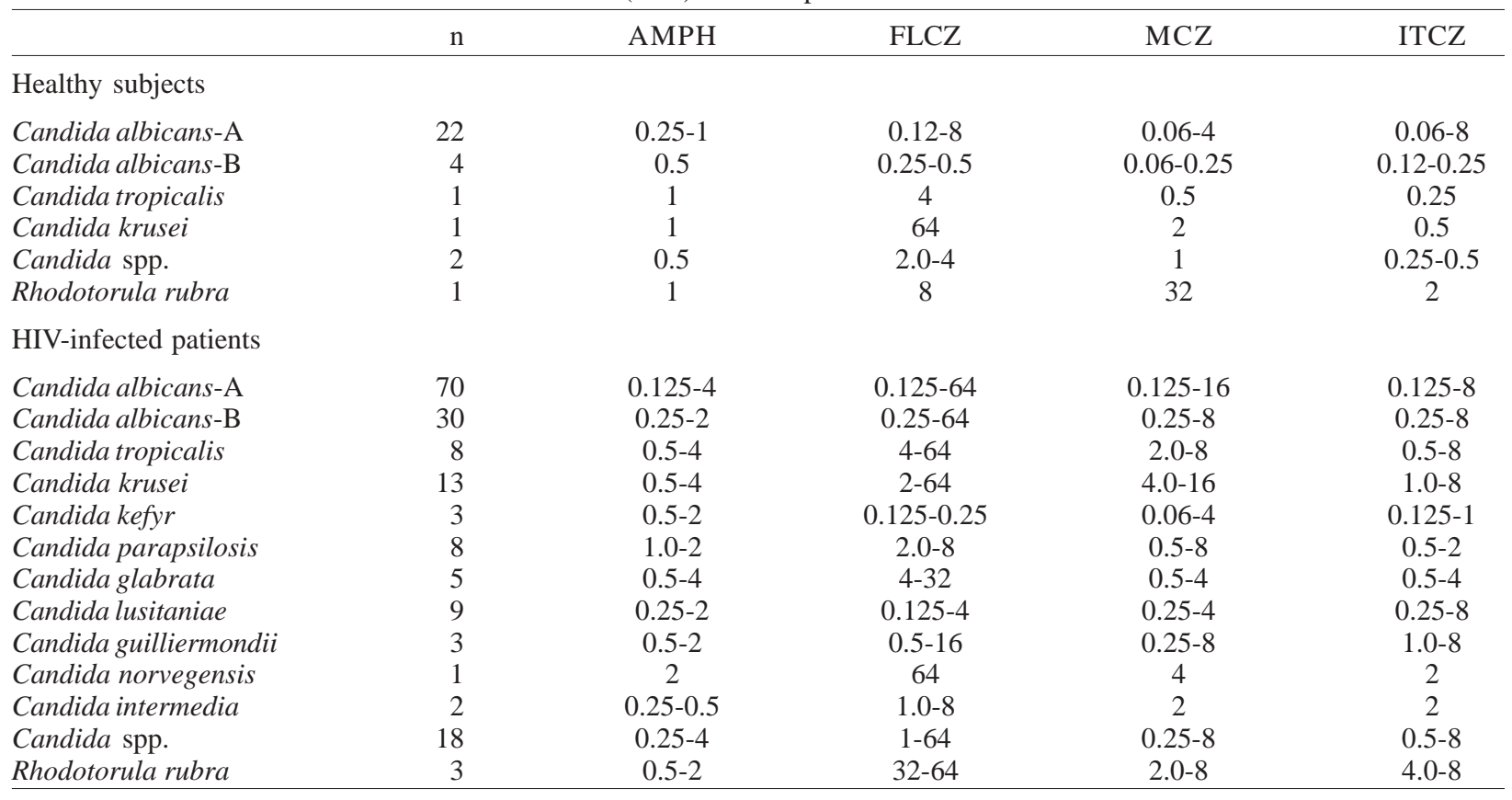

AMPH: amphotericin B; FLCZ: fluconazole; MCZ: miconazole; ITCZ: itraconazole 
C. albicans in isolates from Brazilian HIV-infected patients under HAART.

\section{ACKNOWLEDGMENTS}

To Chiba University, Japan, Dental Faculty of Piracicaba, DST/AIDS Research Group (GPD); Dr Ademar Yamanaka from Gastrocentro, FCM, University of Campinas, Brazil, Dr Stephen N Smith from Aston University, and Samirah Perally, University of Wales Aberystwyth, UK for proof-reading of this paper.

\section{REFERENCES}

Arribas JR, Hernandez-Albujar S, Gonzalez-Garcia JJ, Pena JM, Gonzalez A, Canedo T, Madero R, Vazquez JJ, Powderly WG 2000. Impact of protease inhibitor therapy on HIV-related oropharyngeal candidiasis. AIDS 4: 979 -85 .

Barchiesi F, Maracci M, Radi B, Arzeni D, Baldassarri I, Giacometti A, Scalise G 2002. Point prevalence, microbiology and fluconazole susceptibility patterns of yeast isolates colonizing the oral cavities of HIV-infected patients in the era of highly active antiretroviral therapy. J Antimicrob Chemother 50: 999-1002.

Beighton DRL, Clark DT, Brailsford SR, Pankhurst CL, Tinsley GF, Fiske J, Lewis D, Daly B, Khalifa N 1995. Use of CHROMagar Candida medium for isolation of yeasts from dental samples. J Clin Microbiol 33: 3025-3027.

Billon-Grand G 1987. Minor ubiquinones of the yeast coenzime Q system: importance in the taxonomy of the yeast. J Gen Microbiol 33: 381-390.

Cartledge JD, Midgley J, Gazzard BG 1999. Non-albicans oral candidosis in HIV-positive patients. J Antimicrob Chemother 43: 419-22.

Cassone A, De Bernardis F, Torosantucci A, Tacconelli E, Tumbarello M, Cauda R 1999. In vitro and in vivo anticandidal activity of human immunodeficiency virus protease inhibitors. J Infect Dis 180: 448-53.

CDC 1993. Revised classification system for HIV infection and expanded surveillance case definition for AIDS among adolescents and adults. MMWR 41: 1-19.

Colombo AL, Nucci M, Salomao R, Branchini ML, Richtmann R, Derossi A, Wey SB 1999. High rate of non-albicans candidemia in Brazilian tertiary care hospitals. Diagn Microbiol Infect Dis 34: 281-286.

Diz Dios P, Ocampo A, Otero I, Iglesias I, Martinez C 2001. Changes in oropharyngeal colonization and infection by Candida albicans in human immunodeficiency virus-infected patients. J Infect Dis 183: 355-356.

Dronda F, Alonso-Sanz M, Laguna F, Chaves F, Martinez-Suarez JV, Rodriguez-Tudela JL, Gonzalez-Lopez A, Valencia E 1996. Mixed oropharyngeal candidiasis due to Candida albicans and non-albicans Candida strains in HIV-infected patients. Eur J Clin Microbiol \& Infect Dis 15: 446-452.

Fetter A, Partisani M, Koenig H, Kremer M, Lang JM 1993. Assyntomatic oral Candida albicans carriage in HIV-infection: frequency and predisposing factors. J Oral Pathol Med 2: 57-9.

Fidel PL, Vazquez JrJA, Sobel JD 1999. Candida glabrata: review of epidemiology, pathogenesis, and clinical disease with comparison to C. albicans. Clin Microbiol Rev 12: 8096.

Fotos PG, Hellstein JW 1992. Candida and candidosis. Epidemiology, diagnosis and therapeutic management. Dent Clin North Am 36: 857-878.

Franker CK, Lucartorto FM, Johnson BS, Jacobson JJ 1990. Characterization of the mycoflora from oral mucosal sur- faces of some HIV-infected patients. Oral Surg, Oral Med, and Oral Pathol 69: 683-687.

Fukuoka T, Johnston DA, Winslow CA, Groot MJ, Burt C, Hitchcock CA, Filler SG 2003. Genetic basis for differential activities of fluconazole and voriconazole against $\mathrm{Can}$ dida krusei. Antimicrobial Agents and Chemother 47: 121319.

Fukushima K, Takizawa K, Okada K, Maebayashi Y, Nishimura K, Myiaji M 1993. Suitability of sterilization methods for ubiquinone analysis of pathogenic fungi. Trans Mycol Soc of Japan 34: 473-480.

Ghannoum MA, Rice LB 1999. Antifungal agents: mode of action, mechanisms of resistance, and correlation of these mechanisms with bacterial resistance. Clin Microbiol Rev 12: 501-517.

Hauman CH, Thompson IO, Theunissen F, Wolfaardt P 1993. Oral carriage of Candida in healthy and HIV-seropositive persons. Oral Surg, Oral Med, and Oral Pathol 76: 570572.

Korting HC, Schaller M, Eder G, Hamm G, Bohmer U, Hube B 1999. Effects of the human immunodeficiency virus (HIV) proteinase inhibitors saquinavir and indinavir on in vitro activities of secreted aspartyl proteinases of Candida albicans isolates from HIV-infected patients. Antimicrobial Agents Chemother 43: 2038-2042.

Krcmery V, Barnes AJ 2002. Non-albicans Candida spp. causing fungaemia: pathogenicity and antifungal resistance. $J$ Hosp Infect 50: 243-60.

Kurtzman CP, Robnett CJ 1997. Identification of clinically important ascomycetous yeasts based on nucleotide divergence in the 5 ' end of the large-subunit (26S) ribosomal DNA gene. J Clin Microbiol 35: 1216-1223.

Le Guennec R, Reynes J, Mallie M, Pujol C, Janbon F, Bastide JM 1995. Fluconazole- and itraconazole-resistant Candida albicans strains from AIDS patients: multilocus enzyme electrophoresis analysis and antifungal susceptibilities. $J$ Clin Microbiol 33: 2732-2737.

Mariano P de L, Milan EP, da Matta DA, Colombo AL 2003. Candida dubliniensis identification in Brazilian yeast stock collection. Mem Inst Oswaldo Cruz 98: 533-8.

Mata-Essayag S, Magaldi S, Hartung de Capriles C, Deibis L, Verde G, Perez C 2001. "In vitro" antifungal activity of protease inhibitors. Mycopathologia 152: 135-42.

NCCLS-National Committee for Clinical Laboratory Standards 1997. Reference method for broth dilution antifungal susceptibility testing of yeasts; document M27-A catalog, Wayne, PA.

Nguyen MH, Peacock JEJr, Morris AJ, Tanner DC, Nguyen ML, Snydman DR, Wagener MM, Rinaldi MG, Yu VL 1996. The changing face of candidemia: emergence of non-Candida albicans species and antifungal resistance. Am J Med 100: 617-623.

Nho S, Anderson MJ, Moore CB, Denning DW 1997. Species differentiation by internally transcribed spacer PCR and HhaI digestion of fluconazole-resistant Candida krusei, Candida inconspicua, and Candida norvegensis strains. J Clin Microbiol 35: 1036-1039.

Odds FC 1984. Ecology and epidemiology of Candida species. Zentralbl Bakteriol A Hyg 257: 207-12.

Pfaller MA, Jones RN, Doern GV, Sader HS, Hollis RJ, Messer SA 1998. International surveillance of bloodstream infections due to Candida species: frequency of occurrence and antifungal susceptibilities of isolates collected in 1997 in the United States, Canada, and South America for the SENTRY Program. The SENTRY Participant Group. J Clin Microbiol 36: 1886-1889. 
Pinjon E, Moran GP, Jackson CL, Kelly SL, Sanglard D, Coleman DC, Sullivan DJ 2003. Molecular mechanisms of itra-conazole resistance in Candida dubliniensis. Antimicrobial Agents Chemother 47: 2424-37.

Redding SW, Kirkpatrick WR, Dib O, Fothergill AW, Rinaldi MG, Patterson TF 2000. The epidemiology of non-albicans Candida in oropharyngeal candidiasis in HIV patients. Spec Care Dentist 20: 178-81.

Rodero L, Losso M, Canteros C, Hochenfellner F, Davel G 1998. Candida dubliniensis: 1st isolation in Argentina. Rev Argent Microbiol 30: 39-41.

Sandven P 1990. Laboratory identification and sensitivity testing of yeast isolates. Acta Odontol Scand 48: 27-36.

Sano A, Vilela MMS, Takahashi I, Fukushima K, Takizawa K, Silva MTN, Uno J, Nishimura K, Miyaji M 2000. Isolation of Candida dubliniensis from the oral cavity of an HIVpositive child from Brazil. Jap J Med Mycol 3: 57-59.

Sant'Ana PL, Milan EP, Martinez R, Telles FQ, Ferreira MS, Alcântara AP, Carvalho MT, Colombo AL 2002. Multicenter
Brazilian study of oral Candida species isolated from Aids patients. Mem Inst Oswaldo Cruz 97: 253-257.

Schoofs AG, Odds FC, Colebunders R, Ieven M, Goossens H 1998. Cross-sectional study of oral Candida carriage in a human immunodeficiency virus (HIV)-seropositive population: predisposing factors, epidemiology and antifungal susceptibility. Mycoses 41: 203-11.

Stenderup A 1990. Oral mycology. Acta Odontol Scand 48: 310.

Sullivan DJ, Westerneng TJ, Heynes KA, Bennet DE, Coleman DC 1995. Candida dubliniensis sp. nov.: phenotypic and molecular characterization of a novel species associated with oral candidosis in HIV-infected individuals. Microbiology 1: 1507-1521.

Sweet SP 1997. Selection and pathogenicity of Candida albicans in HIV infection. Oral Dis 3 (Suppl. 1): S88-95.

Taguchi H, Myiaji M, Nishimura K, Min-Li X 1995. Studies on the synergistic effect of amphotericin B and 5fluorocytosine on the growth of single hyphae of $A$. fumigatus a biocell-tracer system. Mycoscience 36: 341-343. 
